\title{
Eficiência de combate aos incêndios florestais em Unidades de Conservação brasileiras
}

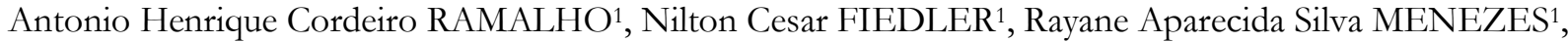 \\ Leonardo Duarte BIAZATTI ${ }^{1}$, Flávio Cipriano de Assis do CARMO², Elaine Cristina Gomes da SILVA ${ }^{3}$
}

\author{
${ }^{1}$ Departamento de Ciências Florestais e da Madeira, Universidade Federal do Espírito Santo, Jerônimo Monteiro, ES, Brasil. \\ ${ }^{2}$ Unidade Acadêmica de Engenharia Florestal, Universidade Federal de Campina Grande, Campina Grande, PB, Brasil. \\ ${ }^{3}$ Departamento de Zootecnia, Universidade Federal do Espírito Santo, Alegre, ES, Brasil. \\ *E-mail: henriqueramalho14@gmail.com \\ (ORCID: 0000-0002-0037-5422; 0000-0002-4376-3660; 0000-0001-8646-2430; \\ 0000-0002-9345-8592; 0000-0001-9956-5295; 0000-0003-4214-2042)
}

Recebido em 10/05/2021; Aceito em 23/08/2021; Publicado em 20/09/2021.

\begin{abstract}
RESUMO: A precariedade dos planos de combate aos incêndios florestais, torna o fogo a principal ameaça às Unidades de Conservação. Os Registros de Ocorrência de Incêndios (ROIs) são estratégias para aumentar a eficiência no enfrentamento aos incêndios. Assim, com a presente pesquisa objetivou-se analisar a eficiência de combate aos incêndios florestais em Unidades de Conservação brasileiras. Foram utilizados os ROIs do Sistema Nacional de Informações sobre Fogo referentes ao intervalo de 2010 a 2020. Foram avaliados o número de ROIs completos e incompletos, tipos de detecção, quantidade de área queimada, tempo de detecção, de ataque e de combate. Os resultados evidenciaram que apenas 52,33\% dos ROIs estavam completos e que 2019 foi o ano com mais ROIs completos. Os pontos de observação e a ronda foram os principais métodos de detecção. As unidades de conservação brasileiras sofreram com a destruição de 31.918.617,41 hectares no período analisado, que significa índice de severidade extremo. Conclui-se que as unidades de conservação brasileiras apresentam baixa eficiência de combate aos incêndios florestais, principalmente de ataque inicial e combate, sendo necessário melhorar a eficiência da detecção e combate, infraestrutura, realizar treinamentos e conscientização sobre a importância dos ROIs.
\end{abstract}

Palavras-chave: proteção florestal; registro de ocorrência de incêndios; áreas protegidas.

\section{Firefighting efficiency in Brazilian Protected Areas}

\begin{abstract}
The precariousness of plans to combat forest fires, makes fire the main threat to Protected areas. Fire Occurrence Records (ROIs) are strategies to increase efficiency in fighting fires. Thus, we aimed analyze the efficiency of fighting forest fires in Brazilian Protected Areas. ROIs by National Fire Information System for the period 2010 to 2020 were used. The number of complete and incomplete ROIs, types of detection, amount of area burned, time of detection, attack and combat were evaluated. The results showed that only $52.33 \%$ of the ROIs were complete and that 2019 was the year with the most complete ROIs. Observation points and patrol were the main detection methods. Brazilian protected areas suffered from the destruction of 31,918,617.41 hectares in the analyzed period, which means an extreme severity index. It is concluded that Brazilian protected areas have low efficiency in combating forest fires, mainly in initial attack and combat, and it is necessary to improve the efficiency of detection and combat, infrastructure, conduct training and awareness about the importance of ROIs.
\end{abstract}

Keywords: forest protection; record of fire occurrences; protected areas.

\section{INTRODUÇÃO}

Os Incêndios Florestais são todos os eventos de fogo sem controle, com potencial destrutivo, que ocorrem em algum tipo de vegetação, advindos de ações antrópicas ou de causas naturais (FIEDLER et al. 2020c; RAMALHO et al., 2021a). Para Zaitsev et al. (2016), Adámek et al. (2015), Canzian et al. (2018) e Torres et al. (2017), os incêndios florestais potencializam a fragmentação de povoamentos florestais, a destruição da diversidade biológica, os danos ao solo e aos cursos hídricos, a erradicação de plantios florestais e agrícolas, danificação de máquinas, equipamentos, benfeitorias e instalações físicas e danos à saúde e à vida humana.
Os incêndios florestais são as principais ameaças às Unidades de Conservação brasileiras (RAMALHO et al., 2021b). As unidades de conservação, são consideradas áreas com características naturais relevantes, delimitadas pelo poder público com o objetivo de garantir a conservação e preservação de seus recursos ambientais (BRASIL, 2000).

Porém, de acordo com Torres et al. (2017), nem mesmo os esforços direcionados às políticas ambientais de preservação dessas áreas têm sido capazes de garantir a sua proteção frente aos incêndios florestais. Para Bontempo et al. (2011) isso ocorre em razão de diferentes fatores, entre os quais destaca-se o planejamento direcionado à prevenção e 
combate aos incêndios florestais, que são precários nessas áreas.

Grande parte da problemática que envolve o planejamento de combate dos incêndios florestais, diz respeito à falta de informações confiáveis que permitam a compreensão do comportamento do fogo na vegetação de cada uma das UCs. Essas informações podem ser obtidas por meio de diversas metodologias, como o zoneamento de risco de ocorrência de incêndios (RIBEIRO et al., 2008), a utilização de técnicas de sensoriamento remoto (FERNANDES et al., 2020), coleta de informações de moradores locais ou análise dos dados fornecidos pelos Registros de Ocorrência de Incêndios Florestais (ROIs) conforme Lima et al. (2018).

Segundo Bontempo et al. (2011), os ROIs são estratégias usadas para reduzir a ocorrência de incêndios florestais, por meio do entendimento do perfil desses eventos e do planejamento de sua prevenção e combate. Para Lima et al. (2018), quando o perfil de comportamento dos incêndios florestais é conhecido, torna-se possível elevar a eficiência do combate aos sinistros.

Para Magalhães et al. (2011), Félix; Lourenço (2017) e Lima et al. (2018), a eficiência no combate aos incêndios florestais diz respeito à minimização do tempo envolvido entre as operações de combate, que são: detecção, comunicação, preparação e início das operações, mobilização, implantação de recursos na área da ocorrência e extinção do fogo.

As informações mínimas que devem constar em um ROI para que o mesmo possa ser utilizado no planejamento eficaz de ações mitigadoras contra os incêndios florestais são: data e hora da ocorrência, da detecção, do ataque inicial, do combate e da extinção das chamas, quantidade de área queimada, prováveis causas, local de ocorrência e tipo de vegetação atingida (TETTO et al., 2015). Os registros devem ser preenchidos, preferencialmente, durante a ocorrência dos incêndios ou logo após o combate. No entanto, para Bontempo et al. (2011), são raras as vezes onde os ROIs são preenchidos com o rigor necessário e muitas vezes os responsáveis pelo preenchimento não registram os dados necessários, ocasionando prejuízos à sua qualidade e confiabilidade, interferindo nas análises da eficiência do combate aos incêndios florestais em UC (SOARES, 2009). Tais registros inadequados tornam-se um problema que deve ser solucionado o mais rápido possível, tendo em vista que, uma base contínua e sólida de informações é fundamental para o planejamento e prevenção da ocorrência de incêndios florestais (FIEDLER et al., 2020a).

Assim, a hipótese que norteia a presente pesquisa é que, quanto maior for o número de registros de ocorrência de incêndios corretamente preenchidos, maior será a eficiência do combate aos incêndios florestais. Dessa forma, com o presente estudo objetivou-se a realização da análise da eficiência de combate aos incêndios florestais em unidades de conservação brasileiras mediante informações disponibilizadas pelos registros de ocorrência de incêndios.

\section{MATERIAL E MÉTODOS}

\section{1. Área de estudo}

O estudo foi conduzido a partir dos dados referentes aos Registros de Ocorrências de Incêndios (ROIs) das Unidades de Conservação federais pertencentes ao Sistema Nacional de Unidades de Conservação (SNUC), do período de 2010 a
2020, disponíveis no endereço eletrônico do Sistema Nacional de Informações sobre Fogo (Sisfogo) do Centro Nacional de Prevenção aos Incêndios Florestais (Prevfogo), gerenciado pelo Instituto Brasileiro do Meio Ambiente e dos Recursos Naturais Renováveis (IBAMA 2020).

\subsection{Organização do banco de dados}

O banco de dados original adquirido no Sisfogo, continha um total de 49.118 Registros de Ocorrência de Incêndios para o período analisado. No entanto, devido à grande quantidade de registros incompletos ou preenchidos inadequadamente, realizou-se um procedimento de organização do qual apenas aqueles registros que continham todos os dados referentes aos parâmetros necessários para a avaliação da eficiência de combate, permaneceram no banco de dados da pesquisa.

Para serem classificados como passíveis de avaliação, os ROIs teriam que conter os seguintes dados: Unidade da Federação de ocorrência (UF); Provável Causa (PC); Tipo de Detecção (D); Data e Hora do Início do Fogo $\left(\mathrm{DH}_{\mathrm{i}}\right)$; Data e Hora de Detecção $\left(\mathrm{DH}_{\mathrm{d}}\right)$; Data e Hora do Primeiro Ataque $\left(\mathrm{DH}_{\mathrm{a}}\right)$; Data e Hora da Extinção $\left(\mathrm{DH}_{\mathrm{e}}\right)$; e Quantidade de área queimada (QA).

\subsection{Parâmetros avaliados}

Inicialmente, realizou-se a análise de frequência acerca do número de registros de ocorrência de incêndios entre os anos 2010 a 2020, do tipo de detecção e do número de ROIs completos e incompletos por estado. Para analisar a eficiência de combate aos incêndios florestais, o primeiro parâmetro avaliado foi a área queimada.

Além da área queimada, o tempo de detecção (TD) também foi um parâmetro avaliado. Esse parâmetro diz respeito ao tempo decorrido entre o início da ocorrência até que sua existência seja detectada e comunicada ao setor responsável pela ação de combate (LIMA et al., 2018), sendo calculado a partir da Equação 1.

$$
\mathrm{TD}=\left(\mathrm{DH}_{\mathrm{d}}-\mathrm{DH}_{\mathrm{i}}\right) \times 24 \times 60
$$

em que: TD é o tempo de detecção (min); $\mathrm{DH}_{\mathrm{d}}$ é a data e hora da detecção; $\mathrm{DH}_{\mathrm{i}}$ é a data e hora do início do fogo).

Outro parâmetro avaliado foi o tempo de ataque (TA). De acordo com Lima et al. (2018), o tempo do primeiro ataque, diz respeito ao tempo decorrido desde a detecção até o início do combate ao incêndio (Equação 2).

$$
\mathrm{TA}=\left(\mathrm{DH}_{\mathrm{a}}-\mathrm{DH}_{\mathrm{d}}\right) \times 24 \times 60
$$

em que: TA é o tempo de ataque (min); $\mathrm{DH}_{\mathrm{a}}$ é a data e hora do primeiro ataque (valor decimal); $\mathrm{DH}_{\mathrm{d}}$ é a data e hora da detecção (valor decimal).

O tempo de duração do combate (TC) também foi avaliado na presente pesquisa (Equação 3). Lima et al. (2018) traduzem esse parâmetro como o tempo decorrido entre o primeiro ataque e a completa extinção dos incêndios.

$$
\mathrm{TC}=\left(\mathrm{DH}_{\mathrm{e}}-\mathrm{DH}_{\mathrm{a}}\right) \times 24 \times 60
$$

em que: TC é o tempo de duração do combate (min); $\mathrm{DH}_{\mathrm{e}}$ é a data e hora da extinção do incêndio; $\mathrm{DH}_{\mathrm{a}}$ (valor decimal) é a data e hora do primeiro ataque (valor decimal). 
A distribuição das classes de eficiência dos sistemas de combate aos incêndios florestais por meio da área queimada, tempo de detecção, tempo de ataque e tempo de combate está apresentada na Tabela 1.

Tabela 1. Classificação da eficiência dos sistemas de combate aos incêndios florestais por meio da quantidade área atingida, tempo de detecção, tempo de ataque e tempo de combate.

Table 1. Classification of the efficiency of forest fire-fighting systems by the amount of area affected, time of detection, time of attack and time of combat.

\begin{tabular}{ccc}
\hline QA (ha) & Classe & Índice de severidade \\
\hline 0 a 0,09 & I & Muito pouco severo \\
0,1 a 4,0 & II & Pouco Severo \\
4,1 a 40,0 & III & Severo \\
41,0 a 200,0 & IV & Muito Severo \\
$>200,0$ & V & Extremo \\
\hline TD (min) & Classe & Eficiência da detecção \\
\hline 0 a 7,5 & I & Muito eficiente \\
7,51 a 15 & II & Eficiente \\
15,1 a 22,5 & III & Pouco eficiente \\
22,6 a 30 & IV & Ineficiente \\
$>30$ & V & Extremamente ineficiente \\
\hline TA (min) & Classe & Eficiência do ataque \\
\hline 0 a 30 & I & Muito eficiente \\
31 a 60 & II & Eficiente \\
61 a 120 & III & Pouco eficiente \\
121 a 480 & IV & Ineficiente \\
$>480$ & V & Extremamente ineficiente \\
\hline TC (min) & Classe & Eficiência do combate \\
\hline 0 a 60 & I & Eficiente \\
61 a 120 & II & Pouco eficiente \\
121 a 480 & III & Ineficiente \\
$>480$ & IV & Extremamente ineficiente \\
\hline
\end{tabular}

Fonte: Adaptado de Ramsey e Higgins (1981); Lima et al. (2018).

Source: Adapted from Ramsey and Higgins (1981); Lima et al. (2018).

\subsection{Análise estatística}

Os resultados referentes às quantidades de áreas queimadas por região foram analisados considerando como delineamento inteiramente casualizado. Inicialmente os dados foram submetidos aos testes de homoscedasticidade da variância, de normalidade e distribuição dos resíduos. Posteriormente foram processados por meio de uma análise de variância (ANOVA a 99\% de probabilidade) e, quando significativas, as médias foram comparadas pelo teste de Tukey a 99\% de probabilidade.

\section{RESULTADOS}

Após a organização dos dados, restaram 25.705 registros passíveis de avaliação que foram avaliados anualmente para detectar quais foram os anos com maiores e menores números de ROIs corretos. Dessa forma, percebeu-se que 2019 (36,64\%), 2018 (26,14\%) e 2017 (17,62\%) foram, respectivamente, os anos com maiores frequências de ROIs completos. Os demais anos (2010, 2011, 2012, 2013, 2014, 2015, 2016 e 2020) tiveram valores inferiores a 10\% de frequência de registros corretos.

A Tabela 2 representa a redução do número de ROIs, por estado, de acordo com a filtragem dos dados realizados nesta pesquisa. É importante salientar que apesar de a região Sul do Brasil possui diversas Unidades de Conservação, devido às filtragens necessárias para a realização da presente pesquisa, não houveram dados significativos para esta região.

A Tabela 3 apresenta os resultados acerca da frequência do tipo de detecção dos incêndios florestais nas UCs brasileiras no período de 2010 a 2020. As médias da quantidade de área queimada, tempo de detecção, tempo para ataque e tempo para combate nas UCs dentro do período de estudo são observadas na Tabela 4. A Tabela 5 apresenta as frequências de classes de quantidade de área queimada, tempo de detecção, tempo de ataque e tempo de combate.

\section{DISCUSSÃO}

Esta pesquisa conta com diferentes variáveis que influenciam diretamente na avaliação da qualidade e eficiência do combate aos incêndios florestais, desde a detecção até os resultados causados pelos eventos. De acordo com Lima et al. (2018), essa eficiência pode ser traduzida como a otimização do tempo envolvido nas operações (detecção, deslocamento, implantação de recursos de ataque, controle e extinção do fogo), além do entendimento das peculiaridades e potencialidades das equipes e dos equipamentos disponíveis, para cada situação.

Ainda assim, Bontempo et al. (2011) afirmam que, apesar da importância desses dados, dificilmente é aplicado o rigor necessário durante a coleta. Esse fato é corroborado pela Tabela 2, que mostra a relação entre os registros de ocorrência de incêndios florestais, elaborados com o correto preenchimento dos dados.

Outro fato que preocupa é a quantidade de registros preenchidos com inconsistência. Isso é percebido na Tabela 2, que apresenta a relação entre os ROIs totais e os preenchidos como todos os dados necessários. Assim, conclui-se, através dos resultados da Tabela 2, que o estado da Bahia foi o que mais registrou de forma correta as ocorrências de incêndios nos últimos 10 anos e, ainda, que ficou entre os 4 estados que mais preencheram corretamente os ROIs, tendo uma redução de $28,46 \%$, seguido pelos estados do Piauí (6,11\%), Acre (6,74\%) e o estado do Espírito Santo $(7,86 \%)$.

De acordo com a Tabela 2, o estado do Ceará, do Distrito Federal, da Paraíba e do Tocantins foram os estados que mais apresentaram inconsistências no preenchimento dos ROIs entre os anos de 2010 a 2020. A redução observada nesses estados foi de $100 \%$, ou seja, nenhum registro foi preenchido completamente. Os estados que mais chamaram atenção foram: o do Tocantins, que apresentou 1265 registros incompletos e do Amapá, que teve 99,85\% de inconsistência nos 2027 registros elaborados.

Para Torres et al. (2017), quando os ROIs são preenchidos corretamente possibilitam aos gestores a realização de uma análise concisa das causas, dos períodos e dos locais de ocorrência. No entanto, o contrário é verdadeiro, ou seja, a falta de informações pode levar às situações extremas, como o gasto exacerbado com sistemas de proteção (acima do potencial de risco de ocorrência de incêndios) ou investimentos reduzidos com proteção, colocando em risco todo o patrimônio.

Desta forma, ao avaliar a variável de tempo de detecção, percebe-se que o IBAMA está enquadrado na classe $\mathrm{V}$ (Tabela 4) que, de acordo com a classificação expressa na Tabela 1, o sistema é extremamente ineficiente. Ao analisar estado por estado, para entender quais os mais influentes sobre a classificação nacional, nota-se que o estado de 
Rondônia obteve o pior desempenho no tempo de detecção, sendo necessários cerca de 15 mil minutos $(\simeq 10,4$ dias $)$ para que o incêndio fosse detectado e comunicado ao setor responsável pela ação de combate (Tabela 4). Em sequência, estiveram os estados do Mato Grosso (5.716,04 minutos) e Roraima (1.896,85 minutos) (Tabela 4). O estado com sistema de detecção mais eficiente foi o do Espírito Santo com 53,49 minutos (Tabela 4). Percebe-se ainda, a partir da Tabela 5 que, de maneira geral, $57,50 \%$ das ocorrências registradas foram avaliadas como muito eficientes e 42,50\% como extremamente ineficientes em relação ao tempo de detecção do incêndio.

Tabela 2. Análise comparativa do número de Registros de Ocorrência de Incêndios (ROIs) totais e completos por estado causada pela filtragem dos dados proposta na presente pesquisa.

Table 2. Comparative analysis of the number of total and complete Fire Occurrence Records (ROI) by state caused by the data filtering proposed in the present research.

\begin{tabular}{cccc}
\hline UF & ROIs totais & ROIs completos & Redução \\
\hline Acre (AC) & 475 & 443 & 6,74 \\
Amazonas (AM) & 293 & 77 & 73,72 \\
Amapá (AP) & 2.027 & 3 & 99,85 \\
Pará (PA) & 1.203 & 413 & 65,67 \\
Rondônia (RO) & 2.881 & 855 & 70,32 \\
Roraima (RR) & 2.824 & 1.324 & 53,12 \\
Tocantins (TO) & 1.265 & 0 & 100,00 \\
\hline Região Norte (N) & 10.968 & 3.115 & 71,60 \\
\hline Distrito Federal (DF) & 555 & 0 & 100,00 \\
Goiás (GO) & 1.200 & 616 & 48,67 \\
Mato Grosso do Sul (MS) & 2.805 & 955 & 65,95 \\
Mato Grosso (MT) & 4.287 & 920 & 78,54 \\
\hline Região Centro Oeste (CO) & 8.847 & 2.491 & 71,84 \\
\hline Espírito Santo (ES) & 140 & 129 & 7,86 \\
Minas Gerais (MG) & 40 & 20 & 50,00 \\
Rio de Janeiro (RJ) & 36 & 10 & 72,22 \\
\hline Região Sudeste (SE) & 216 & 159 & 26,39 \\
\hline Bahia (BA) & 26.571 & 19.008 & 28,46 \\
Ceará (CE) & 550 & 0 & 100,00 \\
Maranhão (MA) & 831 & 240 & 71,12 \\
Paraíba (PB) & 48 & 0 & 100,00 \\
Pernambuco (PE) & 203 & 123 & 39,41 \\
Piauí (PI) & 606 & 569 & 6,11 \\
\hline Região Nordeste (NE) & 28.809 & 0 & 30,79 \\
\hline Indefinidas & 278 & 25.705 & 100,00 \\
\hline Brasil (BR) & 49.118 & 47,67 \\
\hline
\end{tabular}

Fonte: Adaptado de Sisfogo (2020).

Source: Adapted from Sisfogo (2020).

Em se tratando de regiões, as que obtiveram os piores desempenhos em detecção do incêndio foram: a região Norte (5.098,39 minutos) e a do Centro-Oeste (2.801,42 minutos), conforme Tabela 4. As regiões com melhores desempenhos foram a do Sudeste (254,72 minutos) e do Nordeste $(810,65$ minutos) (Tabela 4). É sabido, a partir da Tabela 1 que, nenhum desses valores de tempo médio de detecção são considerados aceitáveis. Pelo contrário, traduzem o sistema como extremamente ineficientes ( $>30$ minutos). Esses resultados são preocupantes, pois, de acordo com Bao et al. (2015) e Lima et al. (2018), quanto mais precoce for a detecção do incêndio, maiores serão as chances de sucesso durante as fases subsequentes de combate aos incêndios florestais.

Em relação à forma de detecção, é possível visualizar, na Tabela 3, que os sistemas do IBAMA são muito limitados, sendo as principais através dos pontos de observação $(23,09 \%)$, seguida pelas rondas $(20,32 \%)$, outros $(19,60 \%)$ e por telefone $(17,70 \%)$. De acordo com Fernandes et al. (2020), dispor de métodos rápidos de detecção de incêndios florestais é uma estratégia eficiente de redução dos danos causados pelas chamas e dos custos de operações de combate.

Técnicas sofisticadas como a utilização de monitoramento por imagens de satélite, sistema de câmeras de alta resolução com imagens ópticas, infravermelhas ou térmicas, sistemas baseados em sensores e Internet (ALKHATIB, 2014), possuem uma boa resposta à problemática da ineficiência da detecção dos incêndios florestais quando comparadas às técnicas que dependem das potencialidades humanas. Em países europeus, como Portugal e Espanha, um sistema que tem apresentado alta eficiência na detecção de incêndios florestais é o "Forest Fire Finder" (ALMEIDA; VIEIRA, 2017). Esse sistema detecta os incêndios nos primeiros cinco minutos e, por ser autônomo e automático, dispensa a observação humana e apresenta alta eficiência devido ao baixo número de falsos alarmes, quando comparado com sistemas concorrentes (ALMEIDA; VIEIRA, 2017).

Além do tempo de detecção, outra variável com forte influência sobre a eficiência do combate aos incêndios florestais é o tempo de ataque (MAGALHÃES et al., 2011). 
Fiedler et al. (2020b) atestam que o tempo decorrido desde a detecção até o primeiro ataque ao incêndio está diretamente relacionado ao binômio "tempo x fogo", ou seja, quanto mais rápido for o ataque, maiores são as chances de a atividade surtir efeito. É sempre bom lembrar que essa etapa do combate aos incêndios está diretamente ligada ao tempo de detecção, isso quer dizer que, quanto mais relapso for o sistema monitoramento pior será a resposta do primeiro ataque.

Além do tempo de detecção, as condições de mobilização também exercem grande influência sobre o tempo de ataque (MAGALHÃES et al., 2011). Por isso, é muito importante garantir que os veículos de combate, as estradas de acesso e a sinalização das estradas vicinais estejam com a manutenção atualizada para garantir que os motoristas não desperdicem tempo nem combustível durante o deslocamento (FIEDLER et al., 2020b).
Tabela 3. Frequência dos tipos de detecção de incêndios florestais nas Unidades de Conservação brasileiras entre os anos de 2010 a 2020 .

Table 3. Frequency of types of detection of forest fires in Brazilian Conservation Units between the years 2010 to 2020.

\begin{tabular}{ccc}
\hline Tipo de detecção & $\mathrm{N}$ & $\%$ \\
\hline Denúncia anônima & 116 & 0,45 \\
Durante combate & 406 & 1,58 \\
Indígena & 930 & 3,62 \\
Monitoramento por satélite & 2.806 & 10,92 \\
Morador do entorno & 700 & 2,72 \\
Outros & 5.039 & 19,60 \\
Ponto de observação & 5.936 & 23,09 \\
Ronda & 5.224 & 20,32 \\
Telefone & 4.548 & 17,70 \\
\hline Total & 25.705 & 100 \\
\hline
\end{tabular}

Fonte: Adaptado de Sisfogo (2020).

Source: Adapted from Sisfogo (2020).

Tabela 4. Médias da quantidade de área queimada, tempo de deteç̧ão, tempo para ataque e tempo para combate dos incêndios florestais nas UCs dentro do período de estudo.

Table 4. Averages of the amount of area burned, detection time, time to attack and time to fight forest fires in UCs within the study period.

\begin{tabular}{|c|c|c|c|c|c|c|c|c|c|c|}
\hline UF & $\mathrm{N}$ & QA (ha) & QA/IF (ha) & Clas. & TD (min) & Clas. & TA (min) & Clas. & TC (min) & Clas. \\
\hline $\mathrm{AC}$ & 443 & $11.875,44$ & 26,81 & III & 831,47 & $\mathrm{~V}$ & 77,07 & III & 221,31 & III \\
\hline $\mathrm{AM}$ & 77 & 65,31 & 0,85 & II & 247,79 & V & 264,16 & IV & 722,42 & IV \\
\hline AP & 3 & 30,00 & 10,00 & III & - & - & 60,00 & II & - & - \\
\hline $\mathrm{PA}$ & 413 & $5.238,85$ & 12,68 & III & 289,25 & V & 39,52 & II & 438,31 & III \\
\hline RO & 855 & $22.099,15$ & 25,85 & III & $15.044,63$ & V & $11.698,13$ & V & 949,69 & IV \\
\hline $\mathrm{RR}$ & 1.324 & $62.753,00$ & 47,40 & IV & $1.896,85$ & V & 151,18 & IV & 917,69 & IV \\
\hline $\mathrm{N}$ & 3.115 & $102.061,75$ & $32,76 \mathrm{~b}$ & III & $5.098,39 \mathrm{a}$ & $\mathrm{V}$ & $3.297,93 \mathrm{a}$ & $\mathrm{V}$ & $758,17 \mathrm{~b}$ & IV \\
\hline $\mathrm{GO}$ & 616 & $2.264 .353,92$ & $3.675,90$ & $\mathrm{~V}$ & 848,57 & $\mathrm{~V}$ & 821,49 & $\mathrm{~V}$ & $5.585,42$ & IV \\
\hline MS & 955 & $429.440,46$ & 449,68 & V & $1.253,24$ & V & 272,81 & IV & 352,22 & III \\
\hline MT & 920 & $3.757 .246,60$ & $4.083,96$ & V & $5.716,04$ & $\mathrm{~V}$ & $3.449,66$ & $\mathrm{~V}$ & $4.239,42$ & IV \\
\hline $\mathrm{CO}$ & 2.491 & $6.451 .040,98$ & $2.589,74 \mathrm{a}$ & $\mathrm{V}$ & $2.801,42 \mathrm{a}$ & $\mathrm{V}$ & $1.581,80 \mathrm{a}$ & $\mathrm{V}$ & $3.082,00 \mathrm{a}$ & IV \\
\hline ES & 129 & $4.405,34$ & 34,15 & III & 53,49 & V & 115,35 & III & $6.034,99$ & IV \\
\hline MG & 20 & $5.180,00$ & 259,00 & V & $1.680,00$ & V & $3.780,00$ & V & $46.381,00$ & IV \\
\hline $\mathrm{RJ}$ & 10 & 300,00 & 30,00 & III & - & - & $1.020,00$ & V & $1.980,00$ & IV \\
\hline SE & 159 & $9.885,34$ & $62,17 \mathrm{~b}$ & IV & $254,72 \mathrm{a}$ & $\mathrm{V}$ & $633,21 \mathrm{a}$ & V & $10.854,93 \mathrm{a}$ & IV \\
\hline BA & 19.008 & $24.756 .439,42$ & $1.302,42$ & V & 826,91 & V & $1.745,73$ & V & $12.264,70$ & IV \\
\hline MA & 240 & $465.706,23$ & $1.940,44$ & V & 212,50 & V & 399,00 & IV & $1.344,77$ & IV \\
\hline PE & 123 & $75.317,66$ & 612,34 & V & 124,39 & V & 538,54 & V & $3.326,99$ & IV \\
\hline PI & 569 & $58.166,03$ & 102,23 & IV & 668,04 & $\mathrm{~V}$ & 129,60 & IV & 313,08 & III \\
\hline $\mathrm{NE}$ & 19.940 & $25.355 .629,34$ & $1.271,60 \mathrm{ab}$ & $\mathrm{V}$ & $810,65 \mathrm{a}$ & $\mathrm{V}$ & $1.675,96 \mathrm{a}$ & $\mathrm{V}$ & $11.737,08 \mathrm{a}$ & IV \\
\hline BR & 25.705 & $31.918 .617,41$ & $1.241,73$ & V & $1.855,82$ & $\mathrm{~V}$ & $1.535,14$ & $\mathrm{~V}$ & $5.317,00$ & IV \\
\hline
\end{tabular}

Fonte: Adaptado de Sisfogo (2020). Onde: QA/IF é a quantidade de área queimada por ocorrência de incêndio; e Clas. é a classificação de acordo com a Tabela 1. As médias seguidas por uma mesma letra não diferem estatisticamente (Tukey, $\mathrm{p}>0,01)$.

Source: Adapted from Sisfogo (2020). Where: QA / IF is the amount of area burned due to the occurrence of fire; and Clas. is the classification according to Table 1. The means followed by the same letter do not differ statistically (Tukey, $\mathrm{p}>0.01$ ).

Tabela 5. Frequência das classes de quantidade de área queimada, tempo de detecção, tempo de ataque e tempo de combate. Table 5. Frequency of classes of amount of area burned, detection time, attack time and combat time.

\begin{tabular}{cccccccccc}
\hline \multirow{2}{*}{ Classe } & $\begin{array}{c}\text { Quantidade de área queimada } \\
\text { (ha) }\end{array}$ & \multicolumn{2}{c}{ Tempo de detecção (min) } & \multicolumn{2}{c}{ Tempo de ataque (min) } & \multicolumn{2}{c}{ Tempo de combate (min) } \\
\cline { 2 - 9 } & $\mathrm{N}$ & $\%$ & $\mathrm{~N}$ & $\%$ & $\mathrm{~N}$ & $\%$ & $\mathrm{~N}$ & $\%$ \\
\hline I & 334 & 1,30 & 14.780 & 57,50 & 9.468 & 36,83 & 1.451 & 5,64 \\
II & 3.886 & 15,12 & 0 & 0,00 & 1.692 & 6,58 & 889 & 3,46 \\
III & 4.034 & 15,69 & 0 & 0,00 & 1.172 & 4,56 & 3.359 & 13,07 \\
IV & 3.626 & 14,11 & 0 & 0,00 & 4.173 & 16,23 & 20.006 & 77,83 \\
V & 13.825 & 53,78 & 10.925 & 42,50 & 9.200 & 35,79 & - & - \\
\hline Total & 25.705 & 100 & 25.705 & 100 & 25.705 & 100 & 25.705 & 100 \\
\hline
\end{tabular}

Fonte: Adaptado de Sisfogo (2020).

Source: Adapted from Sisfogo (2020).

Avaliando o tempo de ataque médio das UC brasileiras, percebe-se que, assim como na detecção, houve uma oscilação significativa entre a classe muito eficiente $(36,83 \%)$ e a classe extremamente ineficiente $(35,79 \%)$, conforme 
Tabela 5. Constata-se ainda, que o IBAMA, de maneira geral, apresenta eficiência muito baixa quando o assunto é o tempo de ataque e que, os estados de Rondônia, Minas Gerais e Mato Grosso foram os que apresentaram as piores eficiências para essa variável, demandando, 11.698,13 minutos, 3.780,00 minutos e 3.449,66 minutos respectivamente para efetuar o primeiro ataque aos eventos de incêndios florestais (Tabela 4).

A região Norte foi a mais eficiente entre as avaliadas em relação a área queimada e ao tempo de combate pelo teste Tukey a $1 \%$ de significância (Tabela 4). Os estados do Pará e do Amapá foram os únicos a apresentar tempo de ataque inferior ou igual a 60 minutos (Tabela 4). Félix e Lourenço (2017) afirmam que o tempo de ataque inicial e a presença ou ausência de brigadas são fundamentais para evitar que os pontos de início dos incêndios evoluam para áreas de grande risco e se tornem eventos incontroláveis. Os tempos elevados de ataque inicial podem estar associados às deficiências de detecção, malha viária no interior das unidades de conservação, devido às exigências legais de conservação da biodiversidade e manutenção das características originais da vegetação e do solo daquelas áreas.

Quando se avalia o tempo decorrido entre o ataque inicial e a extinção completa dos incêndios (Tabela 4 e Tabela 5), percebe-se que o IBAMA é extremamente ineficiente, isso ocorre porque, na média, todas as regiões também são classificadas como IV, pela classificação proposta na Tabela 1. Em relação aos estados, apenas o do Acre, Pará, Mato Grosso do Sul e do Piauí demandaram tempos médios inferiores a 480 minutos (Tabela 4). Quanto às unidades de conservação, $77,83 \%$ das ocorrências traduziram o tempo de combate, também como extremamente ineficiente (Tabela 5).

O tempo de combate está ligado diretamente aos fatores ambientais, condições do material combustível, da topografia, do tempo de ataque, do número de combatentes, do treinamento e preparo técnico da brigada, qualidade dos equipamentos e disposição de insumos de combate (FIEDLER et al., 2006; MAGALHÃES et al., 2011). No entanto, a eficiência do combate muitas vezes é resultante não só dos fatores supracitados, mas também dos sistemas de predição do risco de ocorrência de incêndios florestais, dos sistemas de detecção precoce, deslocamento e direcionamento correto dos combatentes.

Em relação às quantidades de áreas queimadas, as Unidades de Conservação (UC) brasileiras sofreram com a destruição de 31.918.617,41 hectares nos últimos 10 anos e 25.705 incêndios registrados (Tabela 4). Para a classificação do índice de severidade dos incêndios, utilizou-se a quantidade de área queimada média por ocorrência (1.241,73 hectares) (Tabela 4) o que culminou no enquadramento da variável na classe $\mathrm{V}$ (Tabela 4) de índice de severidade dos incêndios florestais (extremo) (Tabela 1). Lima et al. (2018) encontraram 613,61 hectares queimados em seu estudo acerca da eficiência do combate aos incêndios florestais em Unidades de Conservação brasileiras, entre os anos de 2008 a 2012. Apesar de ser uma diferença numérica elevada na classificação proposta pelos autores e utilizada na presente pesquisa (Tabela 1), as Unidades de Conservação brasileiras vêm sofrendo desde o ano de 2008 com ocorrências de incêndios com índices de severidade médio extremos $(>200$ ha por ocorrência).

Em relação à frequência de ocorrência das classes de severidade da área queimada, verifica-se, pelos resultados apresentados na Tabela 5 , que em 53,78\% das vezes os incêndios foram extremos (classe V). Ao realizar a análise comparativa entre as regiões brasileiras, é possível afirmar que nenhuma delas se encontra em situação ideal de eficiência de combate em se tratando de área queimada. As maiores eficiências por classe de área queimada foram apresentadas pelas regiões Norte e Sudeste, que tiveram, respectivamente, $48,25 \%$ e $37,11 \%$ dos incêndios nas classes com áreas inferiores a quatro hectares. Contudo, no valor médio, a região Norte (III) obteve classificação mais eficiente que a região Sudeste (IV) (Tabela 4). A região Nordeste teve $63,24 \%$ das ocorrências registradas com área queimada superior a 200 hectares, por isso foi considerada a menos eficiente, para essa variável.

Convém destacar que a ocorrência e a propagação de incêndios dependem primordialmente da infraestrutura de proteção contra incêndios e nem sempre as condições financeiras das unidades de conservação permitem um bom planejamento das atividades, muito menos a aquisição de equipamentos altamente sofisticados ou contratação de brigadas com treinamento especializado. Portanto, não há dúvidas de que a criação e efetivação de políticas públicas de combate aos incêndios e o direcionamento correto dos recursos para ações que envolvam o cuidado e a proteção ambiental são os principais caminhos para reverter os problemas gerados pela ineficiência dos sistemas de combate aos incêndios florestais em Unidades de Conservação.

Além disso, um gargalo encontrado para as UC pela presente pesquisa foi a complexidade na determinação precisa das causas dos incêndios (que normalmente dependem de perícia), necessidade de conhecimento em metodologias que envolvam geoprocessamento para determinar área queimada, bem como a falta de equipamentos de coleta, análise e interpretação de dados como computador e/ou internet para alimentar o banco de dados.

\section{CONCLUSÕES}

A partir dos resultados obtidos, percebe-se que a hipótese não foi confirmada, pois o fato de preencher corretamente os registros de ocorrência de incêndio não garantem que a Unidade de Conservação possui infraestrutura necessária ou capacidade técnica para elevar a eficiência de combate aos incêndios, haja vista que, o estado da Bahia foi o que apresentou maior percentual de documentos preenchidos corretamente e um dos que tiveram o pior desempenho nas variáveis analisadas;

As Unidades de Conservação brasileiras apresentaram, de modo geral, baixa eficiência de combate aos incêndios florestais, principalmente no que diz respeito ao tempo de ataque e tempo de combate;

O estado mais eficiente dentre os avaliados foi o do Pará, que deteve uma das menores áreas queimadas médias por ocorrência e tempo de ataque eficiente. No entanto, ainda assim, o tempo de combate foi classificado como ineficiente e o tempo de detecção como extremamente ineficiente. O estado da Bahia foi o que apresentou maior quantidade de área queimada entre os anos de 2010 e 2020. O estado de Rondônia, foi o menos eficiente no tempo de ataque e o de Minas Gerais foi o que apresentou maior tempo de combate;

É preciso realizar treinamentos com os brigadistas sobre a importância do preenchimento correto dos registros de ocorrência de incêndios, partindo da constatação de que, apenas metade dos ROIs disponibilizados, estavam completos. 


\section{AGRADECIMENTOS}

Os autores agradecem ao Instituto Brasileiro do Meio Ambiente e dos Recursos Naturais Renováveis (Ibama), ao Sistema Nacional de Informações sobre Fogo (Sisfogo), à Coordenação de Aperfeiçoamento de Pessoal de Nível Superior (CAPES), código de financiamento 001, à Fundação de Amparo à Pesquisa e Inovação do Espírito Santo (FAPES) e ao Conselho Nacional de Desenvolvimento Científico e Tecnológico (CNPq).

\section{REFERÊNCIAS}

ADÁMEK, M.; BOBEK, P.; HADINCOVÁ, V.; WILD, J.; KOPECKÝ, M. Forest fires within a temperate landscape: a decadal and millennial perspective from a sandstone region in central Europe. Forest Ecology and Management, v. 336, p. 81-90, 2015. DOI: 10.1016/j.foreco.2014.10.014

ALKHATIB, A. A. A. A Review on Forest Fire Detection Techniques. International Journal of Distributed Sensor Networks, v. 10, n. 3, p. 1-12, 2014. DOI: 10.1155/2014/597368

ALMEIDA, R. V. de; VIEIRA, D. Forest Fire Finder DOAS application to long-range forest fire detection. Atmos. Meas. Tech., v. 10, p. 2299-2311, 2017. DOI: 10.5194/amt-10-2299-2017

BAO, S.; XIAO, N.; LAI, Z.; ZHANG, H.; KIM, C. Optimizing watchtower locations for forest fire monitoring using location models. Fire Safety Journal, v. $71, \quad$ p. 100-109, 2015. DOI: 10.1016/j.firesaf.2014.11.016

BONTEMPO, G. C.; LIMA, G. S.; RIBEIRO, G. A.; DOULA, S. M.; SILVA, E.; JACOVINE, L. A. G. Registro de Ocorrência de Incêndio (ROI): evolução, desafios e recomendações. Biodiversidade Brasileira, n. 2, p. 247-263, 2011.

BRASIL. Lei Federal No 9.985, de 18 de julho de 2000. Regulamenta o art. 225, \ 1o, incisos I, II, III e VII da Constituição Federal, institui o Sistema Nacional de Unidades de Conservação da Natureza e dá outras providências. Diário Oficial da União, Brasília, DF, 19 jul. 2000. Disponível em: <http://www.planalto.gov.br/ccivil_03/leis/19985.htm >. Acessado em: 09 de maio de 2021.

CANZIAN, W. P.; FIELDER, N. C.; LOUREIRO, E. B.; BERUDE, L. C. Eficiência do uso da água em métodos de combate a incêndios em florestas plantadas. Nativa, v. 6, n.3, p. 309-312, 2018. DOI: $10.31413 /$ nativa.v6i3.4778

FÉLIX, F.; LOURENÇO, L. O tempo de resposta do ataque inicial a incêndios florestais nos espaços mais sensíveis de Portugal. O exemplo prático da Serra da Lousã. Territorium, v. 24, p. 187-211, 2017. DOI: 10.14195/1647-7723_24_14

FERNANDES, L. C.; NERO, M. A.; TEMBA, P.; ELMIRO, M. A. T. Uso de técnicas de sensoriamento remoto utilizando imagens Modis (MCD45A1) para identificação e avaliação de áreas queimadas na Região Metropolitana de Belo Horizonte - MG, Brasil. Sustainability in Debate, v. 11, n. 2, p. 158-172, 2020. DOI: $10.18472 /$ SustDeb.v11n2.2020.28145

FIEDLER, N. C.; RODRIGUES, T. O.; MEDEIROS, M. B. de. Avaliação das condições de trabalho, treinamento, saúde e segurança de brigadistas de combate a incêndios florestais em unidades de conservação do Distrito
Federal: estudo de caso. Revista Árvore, v. 30, n. 1, p. 55-63, 2006. DOI: 10.1590/S0100-67622006000100008

FIEDLER, N. C.; SANT'ANNA, C. M.; TEBALDI, A. L.; MENEZES, R. A. S.; RAMALHO, A. H. C. Causas dos incêndios florestais. In: FIEDLER, N. C.; SANT'ANNA, C. M.; RAMALHO, A. H. C. (Eds.) Incêndios Florestais. 1 ed. Jerônimo Monteiro, ES: UFES: 2020a. p. 55-64. ISBN 978.65.990359-6-8

FIEDLER, N. C.; SANT'ANNA, C. M.; TEBALDI, A. L.; RAMALHO, A. H. C. Métodos de detecção e técnicas de combate aos incêndios florestais. In: FIEDLER, N. C.; SANT'ANNA, C. M.; RAMALHO, A. H. C. (Eds.) Incêndios Florestais. 1 ed. Jerônimo Monteiro, ES: UFES: 2020b. p. 153-194. ISBN 978.65.990359-6-8

FIEDLER, N. C; LACERDA, G. R.; RAMALHO, A. H. C.; BERUDE, L. C.; NEVES, F. P. da; RODRIGUES, C. K. Firefighting combat with fire retardants at different concentrations. Floresta, v. 50, n. 1, p. 1107-1112, 2020c. DOI: $10.5380 /$ rf.v50i1.61609

IBAMA - Instituto Brasileiro do Meio Ambiente e dos Recursos Naturais Renováveis. Sisfogo - ROI. 2020. Disponível $<$ http://dadosabertos.ibama.gov.br/dataset/sisfogoregistro-de-ocorrencias-de-incendio-roi>. Acessado em: 09 de maio de 2021.

LIMA, G. S.; TORRES, F. T. P.; COSTA, A. G.; FÉLIX, G. A.; SILVA JÚNIOR, M. R. Avaliação da eficiência de combate aos incêndios florestais em unidades de conservação brasileiras. Floresta, v. 48, n. 1, p. 113-122, 2018. DOI: $10.5380 /$ rf.v48i1.53550

MAGALHÃES, S. R. de; LIMA, G. S.; RIBEIRO, G. A. Avaliação do Combate aos Incêndios Florestais no Parque Nacional da Serra da Canastra. Floram, v. 18, n. 1, p. 80-86, 2011. DOI: 10.4322/floram.2011.025

RAMALHO, A. H. C.; NEDER, E. de C.; FIEDLER, N. C.; MOREIRA, T. R.; SILVA, J. P. M. Geotechnology applied to predict the risk of occurrence of fire in the Atlantic Forest. Revista Ibero Americana de Ciências Ambientais, v. 12, n. 1, p. 707-720, 2021a. DOI: 10.6008/CBPC2179-6858.2021.001.0057

RAMALHO, A. H. C.; SILVA, E. F. da; SILVA, J. P. M.; FIEDLER, N. C.; MAFFIOLETTI, F. D.; BIAZATTI, L. D.; MOREIRA, T. R.; JUVANHOL, R. S.; SANTOS, A. R. dos. Allocation of water reservoirs to fight forest fires according to the risk of occurrence. Journal of Environmental Management, v. 296, p. 113122, 2021 b. DOI: $10.1016 /$ j.jenvman.2021.113122

RAMSEY, G. S.; HIGGINS, D. G. Canadian Forest fire statistics. Ontario, Canadian Forestry Service, 1981. 71p.

RIBEIRO, L.; KOPROSKI, L. de P.; STOLLE, L.; LINGNAU, C.; SOARES, R. V.; BATISTA, A. C. Zoneamento de risco de incêndios florestais para a fazenda experimental do Canguiri, Pinhais (PR). Floresta, v. 38, n. 3, p. 561-572, 2008. DOI: $10.5380 /$ rf.v38i3.12430

SOARES, R. V. Estatísticas dos incêndios florestais no Brasil. In: SOARES, R. V.; NUNES, J. R. S.; BATISTA, A. C., editores. Incêndios florestais no Brasil - o estado da arte. Curitiba, PR: UFPR, 2009. p. 1-20.

TETTO, A. F.; SOARES, R. V.; BATISTA, A. C.; WENDLING, W. T. Incêndios florestais atendidos pela Klabin do Paraná no período de 1965 a 2009. Cerne, v. 21, n. 3, p. 345-351, 2015. DOI: 10.1590/01047760201521031682 
TORRES, F. T. P.; LIMA, G. S.; COSTA, A. das G.; FÉLIX, G. de A.; SILVA JÚNIOR, M. R. da. Perfil dos incêndios florestais em unidades de conservação brasileiras no período de 2008 a 2012. Floresta, v. 46, n. 4, p. 531-541, 2017. DOI: $10.5380 /$ rf.v46i4.44199
ZAITSEV, A. S.; GONGALSKY, K. B.; MALMSTRÖM, A.; PERSSON, T.; BENGTSSON, J. Why are forest fires generally neglected in soil fauna research? A mini-review. Applied Soil Ecology, v. 98, p. 261-271, 2016. DOI: 10.1016/j.apsoil.2015.10.012 